\title{
Edaravone Inhibits DNA Peroxidation and Neuronal Cell Death in Neonatal Hypoxic-Ischemic Encephalopathy Model Rat
}

\author{
YUJI TAKIZAWA, TAKAHITO MIYAZAWA, SHIGEAKI NONOYAMA, YU-ICHI GOTO, AND MASAYUKI ITOH
}

Department of Mental Retardation and Birth Defect Research [Y.T., Y.-I.G., M.I.], National Center of Neurology and Psychiatry, Kodaira, Tokyo 187-8502, Japan; Departments of Pediatrics [Y.T., S.N.] and Neurosurgery [T.M.], National Defense Medical College, Tokorozawa, Saitama 359-8513, Japan

\begin{abstract}
Neonatal hypoxic-ischemic encephalopathy (HIE) is the most frequent neurologic disease in the perinatal period. Its major cause is oxidative stress, which induces DNA peroxidation and apoptotic neuronal death. We examined 8-hydroxy-2'-deoxyguanosine (8-OHdG) expression to evaluate brain damage in neonatal HIE and the therapeutic effect of edaravone, a free radical scavenger. Using HPLC and immunohistochemistry, the 8-OHdG levels of neonatal HIE model Sprague-Dawley rats that were subjected to left common carotid artery ligation and 2-h hypoxia significantly increased after $24-48 \mathrm{~h}$ of hypoxic-ischemic (HI) insult, but decreased after $72 \mathrm{~h}$. Moreover, the number of apoptotic cells with terminal deoxynucleotidyl transferase-mediated dUTP nick end labeling and karyorrhexis significantly increased after $24-72 \mathrm{~h}$ of $\mathrm{HI}$ insult. In a therapeutic experiment, edaravone was administered i.p. $(9 \mathrm{mg} / \mathrm{kg}$ ) after HI insult every $24 \mathrm{~h}$. Edaravone reduced both the apoptotic neuronal cell number and 8-OHdG expression after 24-48 h of HI. From a double immunofluorescent study, DNA peroxidation occurred in apoptotic neuronal cells with 8-OHdG expression. Edaravone may inhibit the number of apoptotic neuronal cells and 8-OHdG expression within $48 \mathrm{~h}$ after HI insult. (Pediatr Res 65: 636-641, 2009)
\end{abstract}

$\mathrm{N}$ eonatal asphyxia, which is defined as impairment of gas exchange with metabolic acidosis, often develops into hypoxic-ischemic encephalopathy (HIE) (1). Neonatal HIE is sometimes accompanied with the neurologic sequelae, such as cerebral palsy, mental retardation, and intractable epilepsy, although most cases have no such complication. However, the morbidity of neonatal asphyxia is estimated to be $0.22 \%$ and $13.8 \%$ of the babies afflicted reportedly have neurologic sequelae in Japan (2). Another report estimates the incidence of neonatal asphyxia at $0.1-0.8 \%$ in live births (3). The number of victims is not small. Hence, it is necessary to rescue the immature brain from asphyxia and to assure development without neurologic sequelae.

The pathophysiology of neonatal HIE is mainly glutamate neurotoxicity due to the high concentration of free glutamate in intersynaptic spaces and reduction of energy supply from blood (4). As a result of the latter, mitochondrial release of cytochrome $c$ is induced, which activates apoptosis through the caspase-pathway (5). Actually, asphyxiated brains often demonstrate apoptotic neuronal death (6). Additionally, it was

Received November 13, 2008; accepted January 6, 2009.

Correspondence: Masayuki Itoh, M.D., Ph.D., Department of Mental Retardation and Birth Defect Research, National Center of Neurology and Psychiatry, 4-1-1 Ogawahigashi, Kodaira, Tokyo 187-8502, Japan; e-mail: itoh@ncnp.go.jp

Supported by the Ministry of Health, Welfare and Labor of Japan. recently found that in the early stage after hypoxic-ischemic (HI) insult, reactive oxygen species (ROS), such as nitric oxide and hydroxyl radicals, contribute to apoptotic neuronal death (7-11). ROS, which are induced by oxidative stress, are an important factor in initiating DNA peroxidation, which can directly trigger DNA fragmentation and thereby initiate apoptosis (12). 8-Hydroxy-2'-deoxyguanosine (8-OHdG), which is caused by pathologic oxygen radicals, is a hydroxylated form of guanosine of DNA structure $(13,14)$. Therefore, 8-OHdG measurement may be useful to evaluate DNA damage and neuronal apoptosis in the early stage of HIE (15).

Animal models of neonatal HIE have demonstrated apoptotic neuronal death, and its pathologic mechanism has been discussed. Furthermore, several studies have shown a therapeutic approach. Recently, antioxidative stress agents have been successful in cases of brain circulation insufficiency $(16,17)$. Among them, edaravone (3-methyl-1-phenyl-2pyrazolin-5-one) is thought to be the most beneficial agent for patients with acute ischemic stroke (18). Edaravone can interact with both peroxyl and hydroxyl radicals, followed by the formation of a stable oxidation product through a radical intermediate (19). This scavenging effect cannot only inhibit neuronal apoptosis (20) and lipid peroxidation (21) but may also protect neurons against DNA peroxidation by excess production of ROS.

In this study, we reveal that the $8-\mathrm{OHdG}$ amount is useful to evaluate DNA peroxidation and neuronal cell death in the acute stage of neonatal HIE model rat and demonstrate that edaravone is useful to reduce brain damage.

\section{MATERIALS AND METHODS}

Neonatal hypoxic-ischemic encephalopathy model rat. All experiments were performed with the approval of the Animal Experiment Ethical Committee of the National Center of Neurology and Psychiatry. We used unsexed Sprague-Dawley rat pups (15-21 g; CLEA Japan Inc., Tokyo, Japan) on postnatal-day 7. A model of neonatal HIE was developed at postnatal-day 7 (22). Under anesthesia using isoflurane (Forane; Dainippon Pharma, Osaka, Japan) inhalation, the left common carotid artery was isolated, double ligated, and cut. After recovery for $2-4 \mathrm{~h}$ with their mothers, the pups were exposed to $8 \%$ oxygen with an ambient temperature $36^{\circ} \mathrm{C}$ for $2 \mathrm{~h}$ and then returned to their mothers. The pups were kept in a room $(12 \mathrm{~h} / 12 \mathrm{~h}$ light/dark cycle) until they were killed. The same mother littermates as age-matched controls

\footnotetext{
Abbreviations: 8-OHdG, 8-Hydroxy-2'-deoxyguanosine; EdG, edaravone group; HI, hypoxic-ischemic; HIE, hypoxic-ischemic encephalopathy; LIC, left ipsilateral cortices; RCC, right contralateral cortices; VehG, vehicle group
} 
underwent neither surgical procedure nor hypoxic exposure and were killed at postnatal-day 9.

Tissue preparation. Rat pups were killed at 6, 24, 48, and $72 \mathrm{~h}$ after the hypoxic ischemic insult for histopathological and HPLC analyses. They were anesthetized with diethyl ether and perfused intracardially with normal saline. Decapitated brains (frontal and parietal cortices) were dissected coronally at the level of $1 \mathrm{~mm}$ forward of the pituitary stalk.

For HPLC analysis, we separated the posterior region from the cortex, and froze the damaged cortex (left side) and healthy cortex (right side) separately in liquid nitrogen. Frozen samples were preserved at $-80^{\circ} \mathrm{C}$.

For histopathological analysis, the anterior sections of remaining brains were fixed for $24 \mathrm{~h}$ with $4 \%$ paraformaldehyde in PBS at $4^{\circ} \mathrm{C}$ and embedded in paraffin. We made $4-\mu$ m-thick coronal serial sections and performed staining with Nissl, hematoxylin and eosin (H \& E), then TUNEL detection for apoptosis and immunohistochemistry, as well as immunofluorescent double staining.

HPLC analysis of 8-hydroxy-2'-deoxyguanosine. The 8-OHdG levels of cerebral cortex were measured with a method previously described $(23,24)$. Briefly, nuclear DNA was isolated with a DNA extractor WB kit (Wako Pure Chemical Industries, Osaka, Japan) and digested into deoxynucleotides by treatment with nuclease P1 enzyme (Yamasa Corp., Chiba, Japan) and alkaline phosphatase (Sigma-Aldrich Chemical Co., St. Louis, MO). The concentration of $8-\mathrm{OHdG}$ is defined as an $8-\mathrm{OHdG}$ volume/(deoxyguanosine volume $\times 10^{5}$ ) with HPLC (Ultrasphere-ODS, $5 \mu \mathrm{m}, 4.6 \times 250 \mathrm{~mm}^{2}$; Beckman Coulter, Fullerton, CA) and an electrochemical detection system (CoulArray Detector 5600A; ESA, Bedford, MA).

TUNEL assay and immunohistochemistry. TUNEL was performed using Klenow FragEL DNA Fragmentation Detection Kit (Calbiochem, Cambridge, MA) for apoptotic cell counting and In Situ Cell Death Detection Kit, Fluorescein (Roche, Mannheim, Germany) for immunofluorescent double staining.

For immunohistochemistry, the mouse MAb against 8-OHdG (dilution of 1:50; JaICA Inc., Fukuroi, Japan) was incubated for two overnights at $4^{\circ} \mathrm{C}$ (25). We confirmed specificity of the anti-8-OHdG antibody to react positively on a mouse hepatocellular carcinoma tissue. We used aminoethyl carbazole (Nichirei, Tokyo, Japan) as a chromogen to detect the immunoreactivity. For immunofluorescence, the primary antibodies against glial fibrillary acidic protein (GFAP, 1:1000; DAKO, Glostrup, Denmark) and neuron specific enolase (NSE, 1:400; Biomol, Plymouth, MA) were incubated overnight at $4{ }^{\circ} \mathrm{C}$. The stained sections were observed with fluorescence microscope (BX51; Olympus, Tokyo, Japan).

Counting of karyorrhectic cells, TUNEL-positive cells, and 8-OHdGpositive cells. Karyorrhectic cells observed on H \& E, TUNEL-positive cells, and $8-\mathrm{OHdG}$-positive cells were counted in both somatosensory cortices in each of three fields at a magnification of 400 times. We found apoptotic cells to have karyorrhectic features and TUNEL-positivity. The numbers of these marked cells were converted into percent number in each section. The denominator of the ratio was decided to be the number of all nuclei in each field observed. Then we calculated the average and SD as the concentration in each individual.

Drug preparation and administration. Pups were divided into three groups, the vehicle group (VehG), edaravone group (EdG), and control (no treatment) group, consisting of 19, 20, and 8 pups, respectively. After the HI insult, pups of the EdG were immediately administered edaravone (gift from Mitsubishi Tanabe Pharma Inc., Tokyo, Japan) i.p. at a dose of $9 \mathrm{mg} / \mathrm{kg}$ and pups of the VehG with normal saline. The same dose of edaravone or normal saline was then administered every $24 \mathrm{~h}$ until being killed. The dose and time course of edaravone were based on the previous data (26). Rat pups were killed 6, 24, 48, and $72 \mathrm{~h}$ after HI insult. Pups of the control group were killed on postnatal-day 8 and 9 .

Statistical analysis. All data were expressed as average \pm SD. Data were analyzed with ANOVA, followed by Bonferroni's post hoc test. $p<0.05$ was considered as a significant difference.

\section{RESULTS}

\section{Histopathological analysis of apoptotic cell death in cor-} tex. For histologic analysis, we used 4-6 samples at each time point, 6 controls at postnatal-day 9 , and 26 samples were used in total. In the Nissl staining, the left ipsilateral cortices (LIC) demonstrated normal architecture $6 \mathrm{~h}$ after $\mathrm{HI}$ insult (Fig. 1A). However, after $24 \mathrm{~h}$, the cortical damaged area gradually
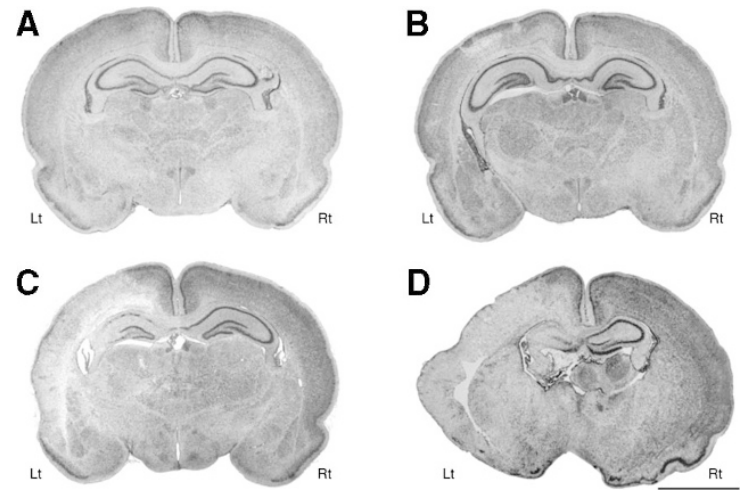

Figure 1. Evolution of brain injury in neonatal HIE with time. Damage to the left ipsilateral brain $(L t)$ worsens gradually over time, whereas the right contralateral brains $(R t)$ show no pathologic changes. Nissl staining of $6 \mathrm{~h}(A)$, $24 \mathrm{~h}(B), 48 \mathrm{~h}(C)$, and $72 \mathrm{~h}(D)$ after HI insult. Scale bar: $2 \mathrm{~mm}$.

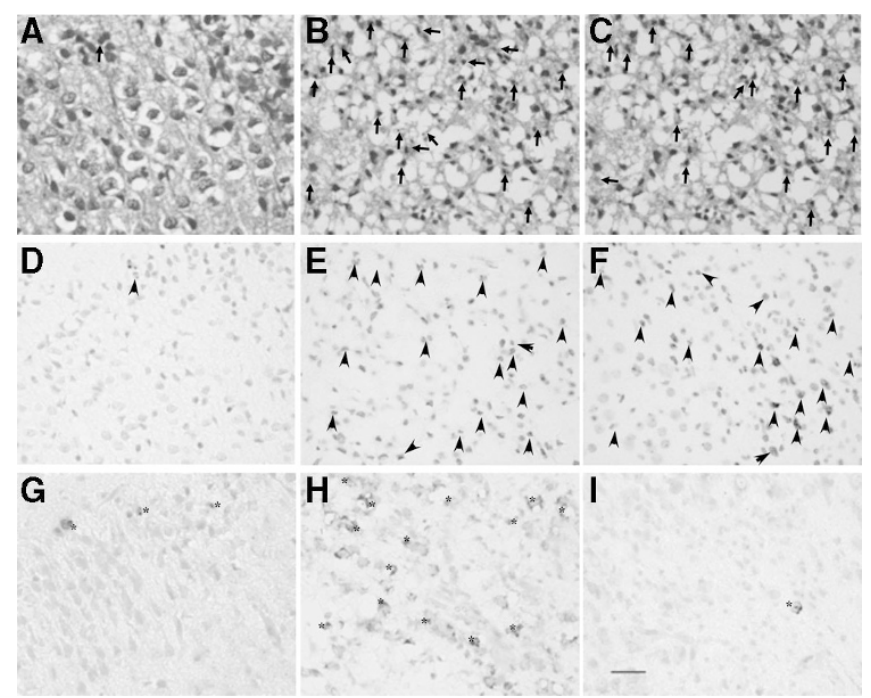

Figure 2. Histologic change of cortical damage with time. Karyorrhectic cells (arrows), TUNEL-positive cells (arrowheads) and cleaved caspase 3 -positive cells appear $6 \mathrm{~h}$ after HI insult, and the numbers increase 48 and $72 \mathrm{~h}$ after $\mathrm{HI}$ insult. 8-OHdG-positive cells (asterisks) also appear $6 \mathrm{~h}$ after HI insult, increase at $48 \mathrm{~h}$, but then decrease at $72 \mathrm{~h}$. All figures are in the ipsilateral cortices. H \& E-stained cells $6 \mathrm{~h}(A), 48 \mathrm{~h}(B)$, and $72 \mathrm{~h}(C)$ after HI insult. TUNEL-positive cells $6 \mathrm{~h}(D), 48 \mathrm{~h}(E)$, and $72 \mathrm{~h}(F)$ after HI. 8-OHdG-positive cells $6 \mathrm{~h}(G), 48 \mathrm{~h}(H)$, and $72 \mathrm{~h}(I)$ after HI. Scale Bar: $25 \mu \mathrm{m}$.

became more extensive and severe, while spreading to the hippocampus, white matter, and striatum (Fig. $1 B-D$ ). The right contralateral cerebrum was normal at all times.

Karyorrhectic cells and TUNEL-positive cells were counted under high magnification $(\times 400)$. These cells gradually increased from $6 \mathrm{~h}$ after $\mathrm{HI}$ insult, and we noticed drastic increases at 48 and $72 \mathrm{~h}$ (Fig. $2 A-F$ ). From the cell counting (Fig. $3 A$ and $B$ ), the percent concentrations of karyorrhectic cells in the LIC and right contralateral cortices (RCC) $24 \mathrm{~h}$ after HI insult were $2.86 \pm 0.65 \%$ of the LIC and $0.07 \pm$ $0.05 \%$ of the RCC $(p<0.001)$, whereas those of TUNELpositive cells at the same time were $3.15 \pm 0.43 \%$ of the LIC and $0.43 \pm 0.15 \%$ of the RCC $(p<0.001)$, respectively. Significant increases were already seen $24 \mathrm{~h}$ after HI insult. Moreover, the concentrations of karyorrhectic cells and 

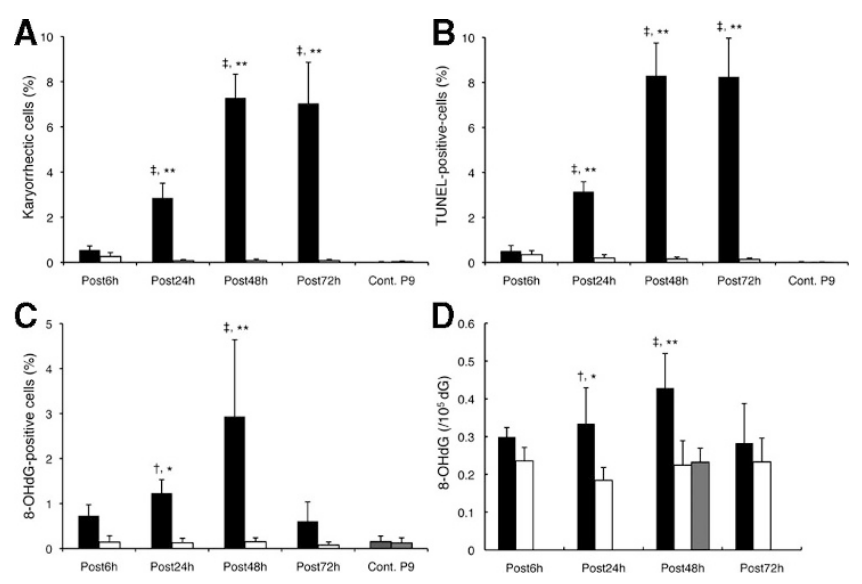

Figure 3. Quantitative analyses of apoptotic cells and 8-OHdG expression in the cortices. In the somatosensory cortices, significant increases of apoptotic cells, which are karyorrhectic $(A)$ and TUNEL-positive $(B)$, are recognized $24 \mathrm{~h}$ after $\mathrm{HI}$ insult and strengthen at 48 and $72 \mathrm{~h}$. There are significant increases of 8-OHdG-positive cell number $(C)$ and concentration $(D$, frontal and parietal cortices) 24 and $48 \mathrm{~h}$ after $\mathrm{HI}$ insult. Six hours after HI insult, significant increases of 8-OHdG-positive cells and concentration are shown. Post $6 \mathrm{~h}$, post $24 \mathrm{~h}$, post $48 \mathrm{~h}$, and post $72 \mathrm{~h}$ mean $6,24,48$, and $72 \mathrm{~h}$ after HI, respectively $(n=4-6)$. $\square$, the left (HI ipsilateral) cortices; $\square$, the right (only hypoxic contralateral) cortices. Controls were killed at postnatal-day $9(\square$, Cont.P9 in $A-C)$ or $48 \mathrm{~h}$ after $\mathrm{HI}$ insult or $(\square$, Post $48 \mathrm{~h}$ in $D)(n=6)$. Data are expressed as average $\pm \mathrm{SD} \dagger p<0.05, \ddagger p<0.001 v$ s. contralateral cortices at the same time. ${ }^{*} p<0.05,{ }^{* *} p<0.001 v s$. ipsilateral cortices $(A-C)$ or left cortices (D) of controls.

TUNEL-positive cells were drastically increased $48 \mathrm{~h}$ after HI insult. The percent concentration of karyorrhectic cells were $7.27 \pm 1.05 \%$ of the LIC and $0.08 \pm 0.07 \%$ of the RCC $(p<$ 0.001 ), and the percent concentration of TUNEL-positive cells were $8.30 \pm 1.45 \%$ and $0.15 \pm 0.09 \%(p<0.001)$, respectively. Seventy-two hours after HI insult, the percent concentration of karyorrhectic cells were $7.03 \pm 1.82 \%$ of the LIC and $0.08 \pm 0.06 \%$ of the RCC $(p<0.001)$, and the percent concentration of TUNEL-positive cells were $8.26 \pm 1.71 \%$ and $0.14 \pm 0.06 \%(p<0.001)$, respectively.

8-hydroxy-2'-deoxyguanosine immunohistochemistry and HPLC for evaluation of DNA peroxidation. The numbers of 8-OHdG-positive cells were increased 24 and $48 \mathrm{~h}$ after HI insult, but decreased at $72 \mathrm{~h}$ (Fig. $2 G-I$ ). The percent concentrations of 8-OHdG-positive cells were $1.23 \pm 0.30 \%$ of the LIC and $0.12 \pm 0.10 \%$ of the RCC at $24 \mathrm{~h}$ after HI insult $(p<$ 0.05 ), and $2.94 \pm 1.71 \%$ of the LIC and $0.15 \pm 0.08 \%$ of the RCC at $48 \mathrm{~h}$ after HI insult $(p<0.001)$ (Fig. 3C). A significant difference was recognized at 24 and $48 \mathrm{~h}$, but not at $72 \mathrm{~h}$. Interestingly, $6 \mathrm{~h}$ after HI insult, the number of 8-OHdGpositive cells obviously tended to increase.

From 8-OHdG measurement with HPLC, the percent concentrations of 8-OHdG significantly increased 24 and $48 \mathrm{~h}$ after $\mathrm{HI}$ insult, at $0.33 \pm 0.10$ of the LIC and $0.18 \pm 0.03$ of the RCC at $24 \mathrm{~h}$ after HI insult $(p<0.05)$, and $0.43 \pm 0.09$ of the LIC and $0.22 \pm 0.06$ of the RCC at $48 \mathrm{~h}$ after HI insult $(p<0.001)$, respectively, per $1 \times 10^{5}$ deoxyguanosine, but decreased at $72 \mathrm{~h}$ (Fig. 3D). This result was consistent with the immunohistochemical data. Moreover, the $8-\mathrm{OHdG}$ level at $6 \mathrm{~h}$ tended to be higher than that of control.
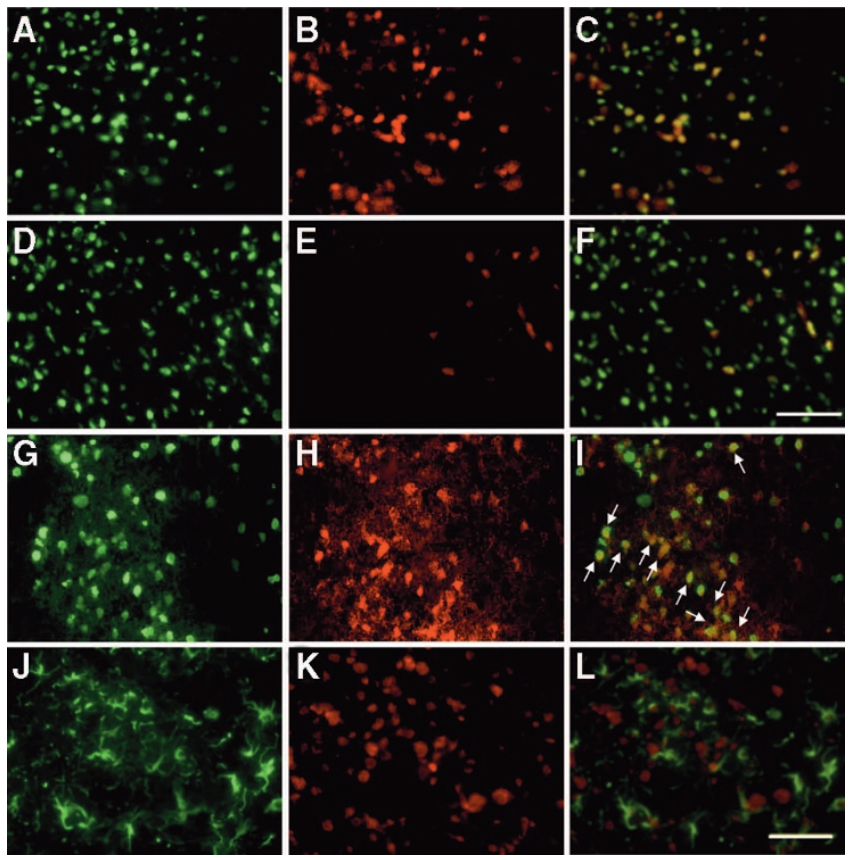

Figure 4. Immunofluorescence of neonatal HIE somatosensory cortices. TUNEL-positive cells are merged with 8-OHdG-positive cells $48 \mathrm{~h}$ after $\mathrm{HI}(A-C)$, but merged cells decrease at $72 \mathrm{~h}(D-F)$. 8-OHdG-positive cells have NSE signals $(G-I)$, but no GFAP signals $(J-L)$. Arrows show cells merged with 8-OHdG and NSE (I). TUNEL-stained ipsilateral cortex $48 \mathrm{~h}$ $(A)$, and $72 \mathrm{~h}(D)$ after $\mathrm{HI}$ insult. 8-OHdG-stained ipsilateral cortex $48 \mathrm{~h}$ $(B)$ and $72 \mathrm{~h}(E)$ after HI insult. Merged image $48 \mathrm{~h}(C)$ and $72 \mathrm{~h}(F)$ after $\mathrm{HI}$ insult. At the cortex $48 \mathrm{~h}$ after HI insult, NSE-stained ipsilateral cortex $(G)$ and GFAP-stained ipsilateral cortex $(J)$. 8-OHdG-stained ipsilateral cortex $(H, K)$. Merged image of $G$ and $H(I)$ and that of $J$ and $K(L)$. Scale bar: $50 \mu \mathrm{m}$.

Immunofluorescent double staining for 8-hydroxy-2'deoxyguanosine localization. We confirmed that $8-\mathrm{OHdG}$ localized in TUNEL-positive cells (Fig. $4 A-F$ ). Forty-eight hours after $\mathrm{HI}$ insult, many cells colocalized with TUNEL and 8-OHdG were observed (Fig. 4A-C). However, doublelabeled cells were clearly fewer in number at $72 \mathrm{~h}$ than at $48 \mathrm{~h}$ (Fig. $4 D-F$ ). This phenomenon may be related to the change in the 8-OHdG-positive cell concentration between 48 and $72 \mathrm{~h}$ after HI insult. Moreover, we could detect 8-OHdG located in NSE-positive cells (Fig. 4G-I), but not in GFAPpositive cells (Fig. $4 J-L$ ). Therefore, it was confirmed that $8-\mathrm{OHdG}$ was located in neurons.

Evaluation of therapeutic effect by edaravone. On the basis of the this result, we conducted edaravone therapy for our neonatal HIE rat pups, using 4-6 samples for each group at each time point and four controls of postnatal-day 8 or 9 . We used 47 samples in total. Macroscopically, compared with the VehG brain, the EdG brain damage was reduced $48 \mathrm{~h}$ after $\mathrm{HI}$ insult (Fig. $5 A$ and $B$ ). Microscopically, karyorrhectic cells, TUNEL-positive cells, and 8-OHdG-positive cells were remarkably decreased in the EdG (Fig. $5 C-H$ ). We also confirmed that the numbers of karyorrhectic cells and TUNELpositive cells were significantly decreased 24,48 , and $72 \mathrm{~h}$ after HI insult in the EdG (Fig. $6 A$ and $B$ ). The percent concentrations of karyorrhectic cells 24,48 , and $72 \mathrm{~h}$ after HI 

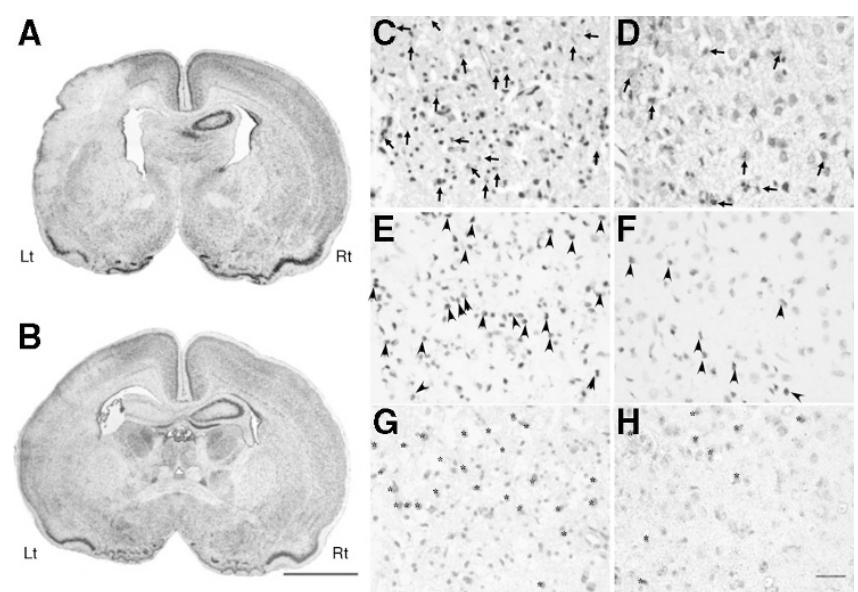

Figure 5. Histopathology of edaravone therapy $48 \mathrm{~h}$ after HI insult. The lesion of edaravone-treated brain $(B)$ is obviously smaller than that of vehicle-treated brain $(A)$. Numbers of karyorrhectic cells (arrows), TUNELpositive cells (arrowheads), and 8-OHdG-positive cells (asterisks) are decreased in edaravone-treated cortices. Nissl staining of vehicle-treated brain slice $(A)$ and edaravone-treated brain $(B) . \mathrm{H} \& \mathrm{E}$ staining of vehicle-treated $(C)$ and edaravone-treated $(D)$ cortices. TUNEL staining of vehicle-treated $(E)$ and edaravone-treated $(F)$ cortices. 8-OHdG staining of vehicle-treated $(G)$ and edaravone-treated $(H)$ cortices. $L t$, the left ipsilateral brain; $R t$, the right contralateral brain. Scale bar: $2 \mathrm{~mm}(A, B) ; 25 \mu \mathrm{m}(C-H)$.
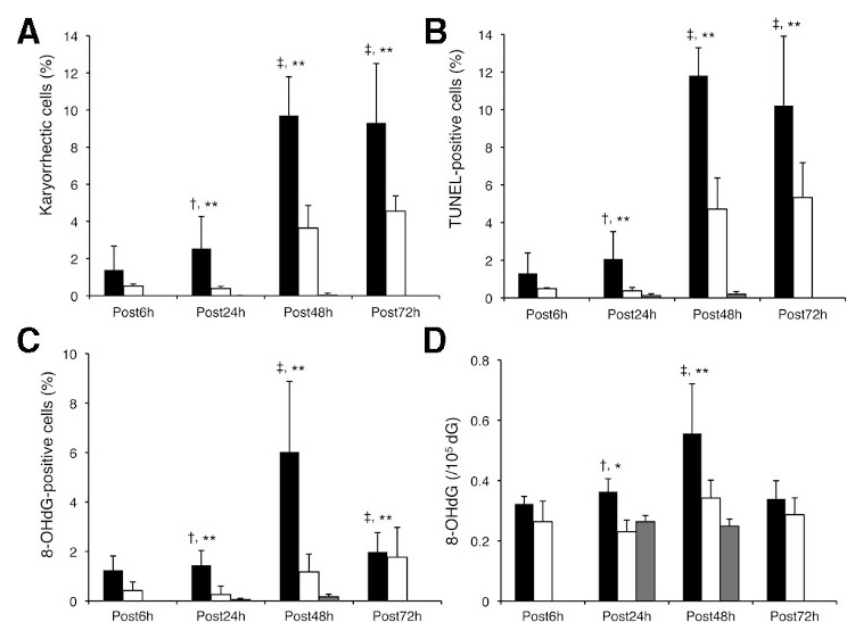

Figure 6. Quantitative analyses of the edaravone-treated cortices. The numbers of karyorrhectic cells $(A)$ and TUNEL-positive cells $(B)$ in the edaravonetreated somatosensory cortices are significantly decreased 24,48 , and $72 \mathrm{~h}$ after $\mathrm{HI}$ insults. The significant differences increase at 48 and $72 \mathrm{~h}$. The number of 8-OHdG-positive cells $(C)$ and concentration ( $D$ : frontal and parietal cortices) in the edaravone-treated cortices are significantly decreased 24 and $48 \mathrm{~h}$ after HI insult, but the differences disappear at $72 \mathrm{~h}$. Post6 h, post $24 \mathrm{~h}$, post $48 \mathrm{~h}$, and post $72 \mathrm{~h}$ mean $6,24,48$, and $72 \mathrm{~h}$ after $\mathrm{HI}$ insult, respectively $(n=4-6)$. Controls in post $24 \mathrm{~h}$ means postnatal-day 8 rats, and control in post $48 \mathrm{~h}$ means postnatal-day $9(n=4$, respectively). Data are expressed as average $\pm \mathrm{SD} \ddagger p<0.05, \ddagger p<0.001 \mathrm{vs}$. edaravone-treated group at the same time. ${ }^{*} p<0.05,{ }^{*} p<0.001 v s$. control groups. $\mathbf{\square}$, VehG; $\square$, EdG; $\square$, control group.

insult were $2.54 \pm 1.72 \%$ of the VehG and $0.38 \pm 0.12 \%$ of the EdG at $24 \mathrm{~h}$ after $\mathrm{HI}$ insult $(p<0.05), 9.71 \pm 2.08 \%$ of the VehG and $3.64 \pm 1.22 \%$ of the EdG at $48 \mathrm{~h}$ after HI insult $(p<0.001)$, and $9.31 \pm 3.19 \%$ of the VehG and $4.55 \pm$ $0.83 \%$ of the EdG at $72 \mathrm{~h}$ after HI insult $(p<0.001)$, respectively. Those of TUNEL-positive cells were $2.07 \pm$
$1.45 \%$ of the VehG and $0.38 \pm 0.17 \%$ of the EdG at $24 \mathrm{~h}$ after HI insult $(p<0.05), 11.80 \pm 1.47 \%$ of the VehG and $4.72 \pm$ $1.66 \%$ of the EdG at $48 \mathrm{~h}$ after HI insult $(p<0.001)$, and $5.33 \pm 3.68 \%$ of the VehG and $0.07 \pm 1.85 \%$ of the EdG at $72 \mathrm{~h}$ after $\mathrm{HI}$ insult $(p<0.001)$, respectively.

In addition, the concentration of 8-OHdG-positive cells in the EdG was significantly inhibited 24 and $48 \mathrm{~h}$ after $\mathrm{HI}$ insult (Fig. 6C). The percent concentrations of 8-OHdG-positive cells were $1.44 \pm 0.60 \%$ of the VehG and $0.26 \pm 0.24 \%$ of the EdG at $24 \mathrm{~h}$ after $\mathrm{HI}$ insult $(p<0.05)$, and $6.02 \pm 2.85 \%$ of the VehG and $1.17 \pm 0.73 \%$ of the EdG at $48 \mathrm{~h}$ after HI insult $(p<0.001)$, respectively. No significant difference was recognized $72 \mathrm{~h}$ after $\mathrm{HI}$ insult.

For the HPLC analysis, we used 4-6 samples for each group. As with the quantitative result, a significant difference was recognized 24 and $48 \mathrm{~h}$ after $\mathrm{HI}$ insult and not demonstrated at $72 \mathrm{~h}$ (Fig. $6 D$ ). The concentrations of $8-\mathrm{OHdG}$ were $0.36 \pm 0.04$ of the VehG and $0.23 \pm 0.04$ of the EdG at $24 \mathrm{~h}$ after $\mathrm{HI}$ insult $(p<0.05)$, and $0.56 \pm 0.16$ of the VehG and $0.34 \pm 0.06$ of the EdG at $48 \mathrm{~h}$ after HI insult $(p<0.001)$ per $1 \times 10^{5}$ deoxyguanosine, respectively.

\section{DISCUSSION}

We demonstrated that in neonatal HIE model rats, the 8-OHdG levels significantly increased after $24-48 \mathrm{~h}$ of HI insult but decreased after $72 \mathrm{~h}$, and the number of apoptotic cells significantly increased after $24-72 \mathrm{~h}$ of HI insult. 8-OHdG measurement may be a useful biochemical tool to evaluate DNA peroxidation and consider neuronal apoptosis within $48 \mathrm{~h}$ of the neonatal HIE event. Moreover, edaravone inhibited both apoptotic neuronal cell number and $8-\mathrm{OHdG}$ expression after $24-48 \mathrm{~h}$ of $\mathrm{HI}$.

Neuronal excitotoxicity due to high-dose glutamate in intersynaptic space is one of the major factors inducing neonatal brain injury (27). Another factor inducing neuronal death, mitochondrial dysfunction, has been known to lead to the apoptotic process (27). This phenomenon is likely to be observed in the immature brain. Oxidative stress is also thought to be one of the major factors to induce neuronal cell death of immature brain.

Among various oxidative stress pathways, DNA peroxidation correlates with apoptotic cell death expansion within $48 \mathrm{~h}$ after HI insult. In adult brain infarction, the 8-OHdG amount reportedly increases in the damaged cortex $24-48$ $\mathrm{h}$ after ischemic insult and decreases at $72 \mathrm{~h}(28,29)$. These findings are compatible with the present results. The early stage change of poly(ADP-ribose) polymerase, a DNA repair-associated enzyme, is similar to that of 8 -OHdG (30). The overexpression of poly(ADP-ribose) polymerase with cleaved caspase- 3 appearance is recognized $24 \mathrm{~h}$ after $\mathrm{HI}$, ends at $72 \mathrm{~h}$, and the expression pattern is steep. Although in dividing cells the damaged DNA is enzymatically repaired with or without $8-\mathrm{OHdG}$ production, postmitotic cells such as neurons show low enzyme activity for DNA repair and are quite vulnerable to a $\mathrm{HI}$ insult (31). Neurons are especially sensitive to ROS, which cause DNA strand breaks (32). It is presumed that when excessive DNA 
peroxidation occurs in neurons, the affected neurons easily fall into DNA repair dysfunction, DNA fragmentation and apoptosis in burst. Our data indicate that DNA peroxidation is the key factor in the drastic increase of neuronal apoptosis at the acute stage of neonatal HIE.

Interestingly, both the number of 8-OHdG-positive cells and the 8-OHdG concentration decreased $72 \mathrm{~h}$ after $\mathrm{HI}$ insult, whereas the number of apoptotic cell deaths did not show an obvious decrease. The apoptotic cells after $48 \mathrm{~h}$ of HI insult can be involved in other factors, such as inflammatory cytokines, in relation to microglial activation. IL-1beta (IL-1 $\beta$ ) expression gradually increases during 1-14 d after $\mathrm{HI}$ insult, and erythropoietin inhibits microglial activation and reduces brain damage (33). On the contrary, under the condition of hypoglycemia and hypoxemia by HI insult, IL- $1 \beta$ directly or indirectly attacks neurons and leads to neuronal cell death (34). Moreover, IL- $1 \beta$ induces microglial activation in cortex $3-4 \mathrm{~d}$ after $\mathrm{HI}$ in the neonatal rat $(35,36)$. This cycle causes many neuronal cell deaths and expansion of lesions. Although we could not detect IL- $1 \beta$ expression, we can speculate that the different pathophysiological changes may take place between events within and after $48 \mathrm{~h}$ of $\mathrm{HI}$ insult. DNA peroxidation plays an important role in forming brain lesions in the early stage of the neuronal death cycle.

Our data demonstrated that edaravone therapy for neonatal HIE inhibits 8-OHdG overexpression at the acute stage, an effect which appears within $48 \mathrm{~h}$ after $\mathrm{HI}$ insult. In this connection, it is very interesting to consider DNA peroxidation from the standpoint of oxidation stress pathology. It is already reported that 2 -d edaravone treatment is more effective than 5-d or 10-d treatment in this model (26). We also showed that $8-\mathrm{OHdG}$ overexpression correlated to apoptotic neuronal cell death within $48 \mathrm{~h}$ after $\mathrm{HI}$ insult.

The edaravone pharmacological mechanism serves to inhibit not only hydroxyl radicals, but also nitrogen oxide (NO) via production of peroxynitrate radicals $(37,38)$. Although NO contributes to the brain damage, it also has neuroprotective roles, promoting vasodilation, and inhibiting microvascular aggregation (39). On the other hand, edaravone may cause some adverse effect with chronic administration. Therefore, in clinical application, the dosing period should be clinically within 2 wk. It is known that edaravone inhibits lipid peroxidation in neonatal HIE rat model (21). Here, we revealed that edaravone also inhibits DNA peroxidation. Edaravone may be a useful agent as a scavenger inhibiting both lipid and DNA peroxidation. Moreover, this study indicates that edaravone treatment should be started immediately within $48 \mathrm{~h}$ after HI insult.

Acknowledgments. We thank Dr. T. Umemura and Ms. M. Tasaki, National Institutes of Health Sciences, Tokyo, Japan, for useful advice on HPLC analysis; Drs. Y. Takei and A. Kondo, Tokyo Medical University, Tokyo, Japan, for supports of animal experience; and Mr. S. Kumagai for technical assistance. We are indebted to Dr. O. Kobayashi for providing the opportunity of this study.

\section{REFERENCES}

1. MacLennan A 1999 A template for defining a causal relation between acute intrapartum events and cerebral palsy: international consensus statement. BMJ 319:1054-1059

2. Asakura H, Ichikawa H, Nakabayashi M, Ando K, Kaneko K, Kawabata M, Tani A, Satoh M, Takahashi K, Sakamoto S 2000 Perinatal risk factors related to neurologic outcomes of term newborns with asphyxia at birth: a prospective study. J Obstet Gynaecol Res 26:313-324

3. American College of Obstetrics and Gynecology 2003 Task Force on Neonatal Encephalopathy. Neonatal Encephalopathy and Cerebral Palsy: Defining the Pathogenesis and Pathophysiology. American College of Obstetrics and Gynecology, Washington, DC, 2003

4. McLean C, Ferriero D 2004 Mechanisms of hypoxic-ischemic injury in the term infant. Semin Perinatol 28:425-432

5. Polster BM, Fiskum G 2004 Mitochondrial mechanisms of neural cell apoptosis. J Neurochem 90:1281-1289

6. Scott RJ, Hegyi L 1997 Cell death in perinatal hypoxic-ischaemic brain injury. Neuropathol Appl Neurobiol 23:307-314

7. Stefanis L 2005 Caspase-dependent and -independent neuronal death: two distinct pathways to neuronal injury. Neuroscientist 11:50-62

8. Ergenekon E, Gücüyener K, Erbaçs D, Süheyl Ezgü F, Atalay Y 1999 Cerebrospinal fluid and serum nitric oxide levels in asphyxiated newborns. Biol Neonate 76:200206

9. Shi Y, Pan F, Li H, Pan J, Qin S, Shen C 2000 Role of carbon monoxide and nitric oxide in newborn infants with postasphyxial hypoxic-ischemic encephalopathy. Pediatrics 106:1447-1451

10. Ogihara T, Hirano K, Ogihara H, Misaki K, Hiroi M, Morinobu T, Kim HS, Ogawa S, Ban R, Hasegawa M, Tamai H 2003 Non-protein-bound transition metals and hydroxyl radical generation in cerebrospinal fluid of newborn infants with hypoxic ischemic encephalopathy. Pediatr Res 53:594-599

11. Warner DS, Sheng H, Batinić-Haberle I 2004 Oxidants, antioxidants and the ischemic brain. J Exp Biol 207:3221-3231

12. Higuchi Y 2003 Chromosomal DNA fragmentation in apoptosis and necrosis induced by oxidative stress. Biochem Pharmacol 66:1527-1535

13. Kasai H, Hayami H, Yamaizumi Z, Saitô H, Nishimura S 1984 Hydroxylation of deoxyguanosine at the $\mathrm{C}-8$ position by ascorbic acid and other reducing agents. Nucleic Acids Res 12:2137-2145

14. Kasai H, Nishimura S 1986 Hydroxylation of guanine in nucleosides and DNA at the C-8 position by heated glucose and oxygen radical-forming agents. Environ Health Perspect 67:111-116

15. Floyd RA 1990 Role of oxygen free radicals in carcinogenesis and brain ischemia. FASEB J 4:2587-2597

16. Shin DH, Bae YC, Kim-Han JS, Lee JH, Choi IY, Son KH, Kang SS, Kim WK, Han BH 2006 Polyphenol amentoflavone affords neuroprotection against neonatal hypoxic-ischemic brain damage via multiple mechanisms. J Neurochem 96:561-572

17. Shimizu K, Rajapakse N, Horiguchi T, Payne RM, Busija DW 2003 Neuroprotection against hypoxia-ischemia in neonatal rat brain by novel superoxide dismutase mimetics. Neurosci Lett 346:41-44

18. Uno M, Kitazato KT, Suzue A, Matsuzaki K, Harada M, Itabe H, Nagahiro S 2005 Inhibition of brain damage by edaravone, a free radical scavenger, can be monitored by plasma biomarkers that detect oxidative and astrocyte damage in patients with acute cerebral infarction. Free Radic Biol Med 39:1109-1116

19. Yamamoto Y, Kuwahara T, Watanabe K, Watanabe K 1996 Antioxidation activity of 3-Methyl-1-phenyl-pyrazolin-5-one. Redox Rep 2:333-338

20. Yasuoka N, Nakajima W, Ishida A, Takada G 2004 Neuroprotection of edaravone on hypoxic-ischemic brain injury in neonatal rats. Brain Res Dev Brain Res 151:129139

21. Noor JI, Ueda Y, Ikeda T, Ikenoue T 2007 Edaravone inhibits lipid peroxidation in neonatal hypoxic-ischemic rats: an in vivo microdialysis study. Neurosci Lett 414:5-9

22. Rice JE, Vannucci RC, Brierley JB 1981 The influence of immaturity on hypoxicischemic brain damage. Ann Neurol 9:131-141

23. Nakae D, Mizumoto Y, Kobayashi E, Noguchi O, Konishi Y 1995 Improved genomic/nuclear DNA extraction for 8-hydroxydeoxyguanosine analysis of small amounts of rat liver tissue. Cancer Lett 97:233-239

24. Kitamura Y, Umemura T, Okazaki K, Kanki K, Imazawa T, Masegi T, Nishikawa A, Hirose M 2006 Enhancing effects of simultaneous treatment with sodium nitrite on 2-amino-3-methylimidazo[4,5-f]quinoline-induced rat liver, colon and Zymbal's gland carcinogenesis after initiation with diethylnitrosamine and 1,2-dimethylhydrazine. Int J Cancer 118:2399-2404

25. Toyokuni S, Tanaka T, Hattori Y, Nishiyama Y, Yoshida A, Uchida K, Hiai H, Ochi H, Osawa T 1997 Quantitative immunohistochemical determination of 8-hydroxy2 -deoxyguanosine by a monoclonal antibody N45.1: its application to ferric nitrotriacetate-induced renal carcinogenesis model. Lab Invest 76:365-374

26. Noor JI, Ikeda T, Mishima K, Aoo N, Ohta S, Egashira N, Iwasaki K, Fujiwara M, Ikenoue T 2005 Short-term administration of a new free radical scavenger, edaravone, is more effective than its long-term administration for the treatment of neonatal hypoxic-ischemic encephalopathy. Stroke 36:2468-2474

27. Johnston MV, Trescher WH, Ishida A, Nakajima W 2001 Neurobiology of hypoxicischemic injury in the developing brain. Pediatr Res 49:735-741

28. Hayashi T, Sakurai M, Itoyama Y, Abe K 1999 Oxidative damage and breakage of DNA in rat brain after transient MCA occlusion. Brain Res 832:159-163 
29. Nagayama T, Lan J, Henshall DC, Chen D, O'Horo C, Simon RP, Chen J 2000 Induction of oxidative DNA damage in the peri-infarct region after permanent focal cerebral ischemia. J Neurochem 75:1716-1728

30. Wang X, Karlsson JO, Zhu C, Bahr BA, Hagberg H, Blomgren K 2001 Caspase-3 activation after neonatal rat cerebral hypoxia-ischemia. Biol Neonate 79:172-179

31. Weissman L, de Souza-Pinto NC, Stevnsner T, Bohr VA 2007 DNA repair, mitochondria, and neurodegeneration. Neuroscience 145:1318-1329

32. Martin LJ 2008 DNA damage and repair: relevance to mechanisms of neurodegeneration. J Neuropathol Exp Neurol 67:377-387

33. Sun Y, Calvert JW, Zhang JH 2005 Neonatal hypoxia/ischemia is associated with decreased inflammatory mediators after erythropoietin administration. Stroke 36:1672-1678

34. Allan SM, Rothwell NJ 2001 Cytokines and acute neurodegeneration. Nat Rev Neurosci 2:734-744
35. Simi A, Lerouet D, Pinteaux E, Brough D 2007 Mechanisms of regulation for interleukin-1beta in neurodegenerative disease. Neuropharmacology 52:1563-1569

36. McRae A, Gilland E, Bona E, Hagberg H 1995 Microglia activation after neonatal hypoxic-ischemia. Brain Res Dev Brain Res 84:245-252

37. Rao P, Maeda H, Yutong X, Yamamoto M, Hirose N, Sasaguri S 2005 Protective effect of a radical scavenger, MCI-186 on islet cell damages induced by oxidative stress. Transplant Proc 37:3457-3458

38. Ono S, Okazaki K, Sakurai M, Inoue Y 1997 Density functional study of the radical reactions of 3-methyl-1-phenyl-2-pyrazolin-5-one (MCI-186): implication for the biological function of MCI-186 as a highly potent antioxidative radical scavenger. J Phys Chem A 101:3769-3775

39. Moro MA, Cárdenas A, Hurtado O, Leza JC, Lizasoain I 2004 Role of nitric oxide after brain ischemia. Cell Calcium 36:265-275 